\title{
Draft Whole Genome Sequence Analyses on Pseudomonas syringae pv. actinidiae Hypersensitive Response Negative Strains Detected from Kiwifruit Bleeding Sap Samples
}

\author{
Enrico Biondi, Alan Zamorano, Ernesto Vega, Stefano Ardizzi, Davide Sitta, Flavio Roberto De Salvador, \\ Reinaldo Campos-Vargas, Claudio Meneses, Set Perez, Assunta Bertaccini, and Nicola Fiore ${ }^{\dagger}$
}

First, fourth, fifth, ninth, and tenth authors: Department of Agricultural Sciences, Plant Pathology, Alma Mater Studiorum-University of Bologna, Bologna 40127, Italy; second and eleventh authors: Universidad de Chile, Facultad de Ciencias Agronómicas, Departamento de Sanidad Vegetal, Santiago 8820808, Chile; third author: Servicio Agrícola y Ganadero, Laboratorios y Estaciones Cuarentenarias, Santiago 9020000, Chile; sixth author: Council for Agricultural Research and Analysis of Agricultural Economics (CREA), Research Centre for Olive, Fruit Trees and Citrus, Roma 00134, Italy; seventh and eighth authors: Universidad Andres Bello, Facultad Ciencias Biologicas, Centro de Biotecnologia Vegetal, Santiago 8370146, Chile; eighth author: FONDAP Center for Genome Regulation, Santiago 8370146, Chile; and ninth author: Universidad de O’Higgins, Instituto de Ciencias Agronómicas y Veterinarias, Rancagua, 2820000, Chile.

Accepted for publication 11 December 2017.

\begin{abstract}
Kiwifruit bleeding sap samples, collected in Italian and Chilean orchards from symptomatic and asymptomatic plants, were evaluated for the presence of Pseudomonas syringae pv. actinidiae, the causal agent of bacterial canker. The saps were sampled during the spring in both hemispheres, before the bud sprouting, during the optimal time window for the collection of an adequate volume of sample for the early detection of the pathogen, preliminarily by molecular assays, and then through its direct isolation and identification. The results of molecular analyses showed more effectiveness in the $P$. syringae pv. actinidiae detection when compared with those of microbiological analyses through the pathogen isolation on the nutritive and semiselective media selected. The bleeding sap analyses allowed the isolation and identification of two hypersensitive response (HR) negative and hypovirulent $P$. syringae pv. actinidiae strains from different regions in Italy. Moreover, multilocus sequence analysis (MLSA) and whole

genome sequence (WGS) were carried out on selected Italian and Chilean $P$. syringae pv. actinidiae virulent strains to verify the presence of genetic variability compared with the HR negative strains and to compare the variability of selected gene clusters between strains isolated in both countries. All the strains showed the lack of $\arg K$ and coronatine gene clusters as reported for the biovar 3 P. syringae pv. actinidiae strains. Despite the biologic differences obtained in the tobacco bioassays and in pathogenicity assays, the MLSA and WGS analyses did not show significant differences between the WGS of the HR negative and HR positive strains; the difference, on the other hand, between PAC_ICE sequences of Italian and Chilean $P$. syringae pv. actinidiae strains was confirmed. The inability of the hypovirulent strains IPVBO 8893 and IPV-BO 9286 to provoke HR in tobacco and the low virulence shown in this host could not be associated with mutations or recombinations in T3SS island.
\end{abstract}

Pseudomonas syringae pv. actinidiae, the etiological agent of bacterial canker of Actinidia species, is up to date classified in four biovars according to phenotypic and pathogenic and molecular characteristics (Cunty et al. 2015b; Sawada et al. 2014; Vanneste et al. 2013). The biovar 1 was first isolated in Japan in 1984 (Serizawa et al. 1989; Takikawa et al. 1989) and Korea (Ciarroni et al. 2015); a few years later, in 1992, a strain belonging to biovar 1 was isolated also in Italy (Scortichini 1994). Biovar 2 was detected in Korea during the 1990s (Koh et al. 1994), while biovar 3 was responsible for the pandemic bacterial canker spread that occurred since 2008 in Europe (Abelleira et al. 2011; Balestra et al. 2008, 2011; NPPO of Switzerland 2011; Vanneste et al. 2010), Asia (Mazzaglia et al. 2012), Oceania (Anonymous 2011a; Everett et al. 2011), and South America (Anonymous 2011b; SAG 2011).

During the last years, the bacteria of the virulent biovar 3 has been characterized through biochemical, physiological, and different molecular assays; in particular, studies were conducted using multilocus sequence analysis (MLSA) (Butler et al. 2013; Chapman et al. 2012) and whole genome sequence (WGS) (Marcelletti et al.

${ }^{\dagger}$ Corresponding author: N. Fiore; E-mail: nfiore@uchile.cl

*The $\boldsymbol{e}$-Xtra logo stands for "electronic extra" and indicates that one supplementary table is published online.

(c) 2018 The American Phytopathological Society
2011; Mazzaglia et al. 2012; Butler et al. 2013; McCann et al. 2013). Biovar 3 was first discriminated from biovars 1 and 2 by its inability to produce phaseolotoxin and coronatine, respectively, where the lack of these virulence factors did not affect the bacterial aggressiveness. The spreading of this virulent biovar, coupled with the increasing cultivation rate of highly susceptible varieties, mostly belonging to $A$. chinensis genotype, was the principal cause of the worldwide outbreaks (EPPO 2014). Susceptibility studies, carried out in several Actinidia species, experimentally inoculated with a $P$. syringae pv. actinidiae biovar 3 strain, confirmed the highest susceptibility of $A$. chinensis genotypes compared with those of A. deliciosa, A. arguta, A. eriantha, and A. hemsleyana (Biondi et al. 2015). Further recent studies, carried out using variable-number of tandem repeats multilocus analysis on the core genome of a large number of bacterial strains, allowed a deeper discrimination of haplotypes in P. syringae pv. actinidiae biovar 3 strains. Moreover, it was demonstrated that, since these strains are monophyletic, the haplotypes isolated in Italy and France originated in China (Butler et al. 2013; Mazzaglia et al. 2012) and are genetically distinguishable from those isolated in Chile and New Zealand (Butler et al. 2013; Cunty et al. 2015b).

Biovar 4, a low virulent group of fluorescent strains isolated in Australia, New Zealand, and France, was thereafter separated from the $P$. syringae pv. actinidiae biovars and assigned to pathovar actinidifoliorum (Cunty et al. 2015a); while biovar 5, recently isolated in Japan and characterized by biochemical, physiological, 
and molecular assays, was clearly formed by different strains and it was proposed as an independent MLSA group (Fujikawa and Sawada 2016; Sawada et al. 2014).

Basically, the control of $P$. syringae pv. actinidiae relies on preventive treatments with copper compounds and use of resistance inducers (Cellini et al. 2014). In the perspective of an integrated pest control management, the production of plants $P$. syringae $\mathrm{pv}$. actinidiae-free and the continuous monitoring of kiwifruit orchards are considered efficient methods to reduce the bacterial inoculum sources (EPPO 2014). P. syringae pv. actinidiae detection at the early disease stages or before the appearance of symptoms is indeed necessary, in particular, the detection of latently infected kiwifruit plants is one of the principal needs, especially taking into account that symptoms do not appear during the first 2 or 3 years of infection (Koh and Nou 2002). Several studies concerning P. syringae pv. actinidiae detection using molecular methods such as PCR (Balestra et al. 2013; Biondi et al. 2013; Gallelli et al. 2011; Koh et al. 2014; Rees-George et al. 2010), qPCR (Gallelli et al. 2014), and loopmediated isothermal amplification (Buriani et al. 2015; Ruinelli et al. 2017) have been proposed.

In this study, several bleeding sap samples were collected during Italian and Chilean vegetative seasons in kiwifruit orchards located in different regions of the two countries. The sampling and the testing aimed to find a time window before bud sprouting, in which to carry out the bleeding sap collection to detect the pathogen early in both hemispheres. Moreover, MLSA and WGS were carried out on Italian and Chilean P. syringae pv. actinidiae strains, and some Italian strains were also assayed for their virulence on yellow kiwifruit plants.

\section{MATERIALS AND METHODS}

Bacterial reference strains. $P$. syringae pv. actinidiae strains NCPPB 3739 (from National Collection of Plant Pathogenic Bacteria, York, UK), CFBP 7286 (from Collection Française de Bactéries Phytopathogènes, INRA Angers, France), CRA-FRU 3.1 (from Culture Collection of C.R.E.A.-Research Centre for Fruit, Roma, Italy), and $P$. syringae pv. actinidifoliorum strain ICMP 19074 (from International Collection of Micro-organisms from Plants, Manaaki Whenua Landcare Research, Auckland, New Zealand) isolated from A. chinensis- and A. deliciosa-infected plants were used as reference strains in microbiological, molecular, and pathogenicity assays. Strains were routinely grown on King's medium B agar (KB) (King et al. 1954) at $27^{\circ} \mathrm{C}$ for $48 \mathrm{~h}$.

Bleeding sap sampling. Bleeding saps were collected, until bud sprouting, during the Italian and Chilean vegetative seasons in 2013. Italian samples were collected in three orchards located in Veneto, Emilia Romagna, and Lazio regions, while in Chile the bleeding saps were collected in three orchards in Maule and Biobío regions. In particular, in Italy, the samples collected in Emilia
Romagna and Veneto were from green-fleshed symptomatic and nonsymptomatic kiwifruit fields, respectively, while in Lazio the samples were collected from asymptomatic yellow-fleshed species. In Chile, the sap samples were all collected from A. deliciosa 'Hayward' asymptomatic plants.

Saps were collected from three marked 1-year-old shoots on different branches of 10 to 12 randomly selected kiwifruit trees (Table 1). The marked shoots were externally sterilized with $70 \%$ ethanol in their 10 to $15 \mathrm{~cm}$ distal part, and then ca. $2 \mathrm{~cm}$ was removed and 15-ml Falcon tubes were fixed to the just open wound to collect the dripping saps. After approximately $2 \mathrm{~h}$, the three samples from each kiwifruit plant were collected, mixed in one 50 -ml Falcon tube, and brought to the laboratory. All samples were centrifuged at $10,000 \times \mathrm{g}$ for $20 \mathrm{~min}$ at $4^{\circ} \mathrm{C}$ and the pellets were resuspended in $1 \mathrm{ml}$ of sterile distilled water (SDW). Three hundred microliters of the resuspension was directly used for DNA extraction and PCR assays and stored at $-20^{\circ} \mathrm{C}$. The remaining $700 \mu \mathrm{l}$ was used for direct isolations, amended with $20 \%$ glycerol, and stored at $-80^{\circ} \mathrm{C}$.

Microbiological analyses. The resuspended bacterial pellets, obtained from bleeding saps, were 10-fold diluted and plated $(50 \mu \mathrm{l})$ onto nutrient sucrose agar (NSA) (Crosse 1959) and onto semiselective NSA (SsNSA) amended with $1.5 \%$ boric acid, 80 ppm cephalexin sulfate, and 120 ppm cycloheximide (EPPO 2014; Gallelli et al. 2011; Stefani and Giovanardi 2011). The plates were incubated at $27^{\circ} \mathrm{C}$ for 72 to $96 \mathrm{~h}$. The $P$. syringae pv. actinidiae-like colonies, isolated from bleeding saps, were characterized by the following biochemical tests: levan production, oxidase presence, soft rot activity on potato disks, presence of arginine dehydrolase, hypersensitive response (HR) in tobacco leaves (LOPAT tests) (Lelliot and Stead 1987; Schaad et al. 2001), and fluorescence on KB medium.

The sensitivity threshold of NSA and SsNSA media was assessed by contaminating nine Eppendorf tubes containing $900 \mu \mathrm{l}$ of $P$. syringae pv. actinidiae-free bleeding sap by adding $100 \mu \mathrm{l}$ of 10-fold dilutions (from approximately $10^{8}$ to $1 \mathrm{CFU} \mathrm{m}{ }^{-1}$ ) of P. syringae pv. actinidiae CRA-FRU 3.1 suspension. The last sample was not contaminated and was used as negative control. One hundred microliters of each dilution was inoculated and spread on NSA and SsNSA plates and incubated at $27^{\circ} \mathrm{C}$ for 72 to $96 \mathrm{~h}$. The grown colonies were then counted to calculate the $P$. syringae $\mathrm{pv}$. actinidiae $\mathrm{CFU} / \mathrm{ml}$ bleeding sap. The experiment was replicated three times.

DNA extraction and molecular assays. DNA was extracted from processed bleeding saps and from aqueous suspensions (ca. $10^{8} \mathrm{CFU} / \mathrm{ml}$ ) of $P$. syringae pv. actinidiae-like colonies by heating the samples at $100^{\circ} \mathrm{C}$ for $15 \mathrm{~min}$. The heat-shocked lysates were then immediately cooled in ice.

On bleeding sap samples collected both in Italy and Chile, PCR and nested-PCR assays were performed in $25-\mu$ l reaction mixtures,

TABLE 1. Sampling collections carried out in Italy and in Chile; the kiwifruit species from which samples were collected are also shown

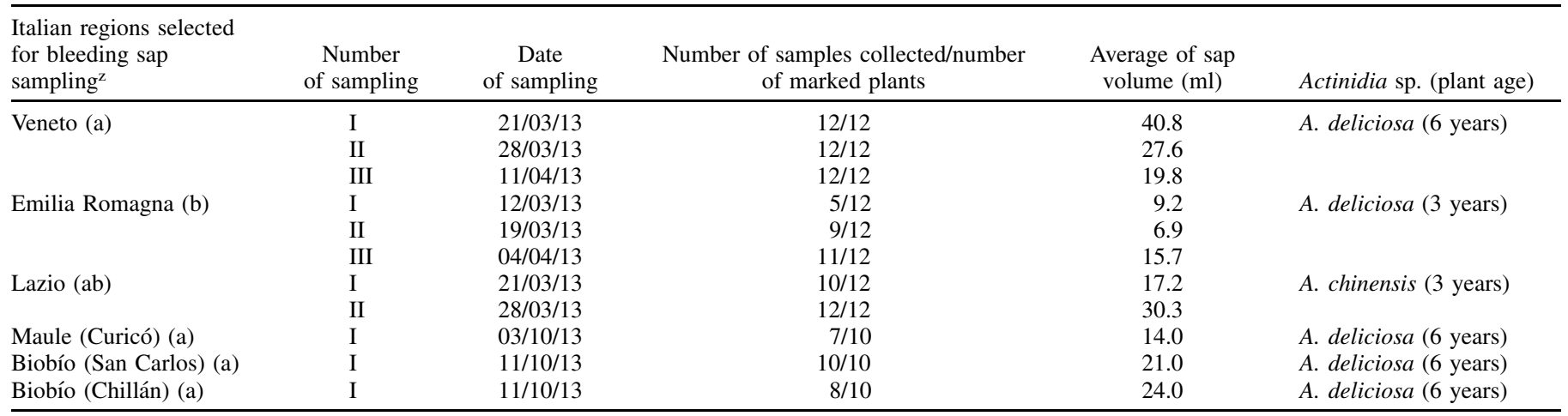

${ }_{\mathrm{z}}$ Letters indicate different statistical categories, related to the mean volume collected in each region, in Italy and Chile. 
following the protocol proposed by Biondi et al. (2013) by adding $2 \%$ BLOTTO (10\% skim milk in $0.2 \% \mathrm{NaN}_{3}$ ) (de Boer et al. 1995) to the chemical profile. Heat-shocked lysates of $P$. syringae pv. actinidiae-like colonies were assayed using different PCR methods (Biondi et al. 2013; Gallelli et al. 2011). SDW was used in all molecular assays as negative control. All amplification products were analyzed on $1.5 \%$ (wt/vol) agarose gel in TAE buffer $(0.04 \mathrm{M}$ Tris, 0.001 M NaEDTA, and 0.02 M glacial acetic acid), stained in $0.03 \%$ ethidium bromide, and visualized under UV light $(312 \mathrm{~nm})$.

MLSA and WGS. Single colonies of five P. syringae pv. actinidiae strains (three isolated in Italy and two in Chile) were grown in LB broth for $24 \mathrm{~h}$ at $27^{\circ} \mathrm{C}$. The $24-\mathrm{h}$ suspensions were centrifuged for $20 \mathrm{~min}$ at $10,000 \times g$ at $4^{\circ} \mathrm{C}$, and the DNA was extracted using GeneJet genomic DNA purification kit (Thermo Fisher Scientific, Lithuania). The strains were assayed by MLSA according to previous studies (Sarkar and Guttman 2004). Seven housekeeping genes were amplified and sequenced by the Sanger method in Macrogen USA Corp. (Rockville, MD). The obtained sequences of $a c n B, c t s, g a p A, g y r B, p f k, p g i$, and $r p o D$ were concatenated and aligned together with reference sequences of $P$. syringae pv. actinidiae and $P$. syringae pv. actinidifoliorum, using ClustalW2. Maximum likelihood (ML) and maximum parsimony analysis were performed using MEGA v 7.0 (Kumar et al. 2016).

For WGS, genomic DNA (gDNA) was extracted using GeneJet genomic DNA purification kit (Thermo Fisher Scientific, Lithuania). DNA integrity was evaluated using capillary electrophoresis (AATI Fragment Analyzer, HS Large Fragment analysis kit, DNF493, AATI, IA). For library construction, sonication of $200 \mathrm{ng}$ of DNA was made on Covaris (model M220), according to Illumina instructions, in a total volume of $50 \mu \mathrm{l}$ of TE buffer. After checking fragmented sizes on Fragment Analyzer, sonicated gDNA was size-selected by Agencourt AMPure XP Beads (Beckman Coulter). The 400 to $500 \mathrm{bp}$ of gDNA was treated with TruSeq Nano DNA Library Prep kit reagents, following Illumina's kit protocol. The final size of the libraries was determined by Fragment Analyzer, concentration was assessed using fluorometric method (Qubit 2.0, BR DNA kit) and finally sequenced using Illumina Miseq system using $2 \times 300$ paired ends system.

Total readings were trimmed and de novo assembled using CLC genomics workbench v7.0. Selected quality trimming limit value was 0.02 , and de novo assembly was performed with a length fraction of 0.6 , and identity value of 0.9 . Assembled contigs were annotated using the Rapid Annotation Subsystem Technologies (RAST) server. Whole genome plasmids and PAC_integrative conjugative element (PAC_ICE) alignments were performed using progressive MAUVE; $\arg K$ (phaseolotoxin) and coronatine gene cluster analyses were performed using CLC genomics workbench. After a WGS, another MLSA analysis was performed on 58 genes coding type three secretion system-related proteins (T3SS) structural (Supplementary Table S1) and effector proteins. Analyzed genes were selected from annotation available for ICMP 18884 strain and compared with Italian and Chilean strain contigs by using BLASTn tool in CLC genomics workbench and by selecting each strain contigs set as a local database. Retrieved sequences were concatenated and aligned with reference strains of $P$. syringae pv. actinidiae and $P$. syringae pv. actinidifoliorum. Phylogenetic analysis was performed with ML method, using CLC genomics workbench.

Pathogenicity assay and virulence evaluation of selected $P$. syringae pv. actinidiae strains. One-year-old kiwifruit plants of cultivar Belèn were grown in 7.0-liter pots, containing a peat and vermiculite soil mix, and pruned to stimulate the emergence of new shoots and young leaves. All the tested plants were inoculated at the same phenological stage. Two plants were then distributed in four randomized blocks and experimentally inoculated by spraying a calibrated water suspension on young leaves containing the selected P. syringae pv. actinidiae strains $\left(0.01 \mathrm{OD}_{600 \mathrm{~nm}}\right.$, ca. $\left.10^{7} \mathrm{CFU} / \mathrm{ml}\right)$. The plants were sealed in polyethylene bags for $48 \mathrm{~h}$ to favor the water congestion and allow the pathogen inoculation. The controlled conditions, hold until disease assessment, were $16 \mathrm{~h}$ of day light and $8 \mathrm{~h}$ of darkness, 23 and $17^{\circ} \mathrm{C}$ during day and night, respectively. The relative humidity was maintained at approximately $90 \%$. Plants sprayed with SDW and noninoculated ones were used as negative control. Water suspensions of reference P. syringae pv. actinidiae biovar 3 strains CFBP 7286 and CRAFRU 3.1 were used as positive control. The hypovirulent strain ICMP 19074 of $P$. syringae pv. actinidifoliorum was also assayed as additional control. The disease severity was evaluated 21 days after $P$. syringae pv. actinidiae inoculation by counting the number of leaf spots on 10 leaves/plant (80 leaves per treatment). The data were analyzed by analysis of variance (Duncan's test, $P \leq 0.05$ ) using software SPSS 15.0 for Windows. The pathogen strains of $P$. syringae pv. actinidiae and $P$. syringae pv. actinidifoliorum were re-isolated onto NSA plates from selected leaf spots, and the isolates were identified through LOPAT tests and molecular assays (Biondi et al. 2013).

\section{RESULTS}

Molecular and microbiological analyses on bleeding sap samples. In the Veneto region (Italy), bleeding saps were collected from all 12 plants selected at each collection time with average volumes of approximately 41, 28, and $20 \mathrm{ml}$ from March to April. In Emilia Romagna, the frequency of collected saps was 5, 9, and 11 out of the 12 plants, with average volumes of approximately 9, 7, and $16 \mathrm{ml}$ from the first to the last collection time. In Lazio, the sap frequency in the two collection dates (in March) was 10 and 12 out of the 12 selected trees, with average volumes of approximately 17 and $30 \mathrm{ml}$ in the first and second collection time, respectively (Table 1).

In Curicó, Chillán, and San Carlos (Chile), the sole collection was carried out at the beginning of October 2013, and different sap frequency and volume, according to the locality, was observed: 7, 8, and 10 out of 10 selected plants were collected, with average volumes of approximately 14, 21, and $24 \mathrm{ml}$, respectively (Table 1).

The direct and nested PCR on the Italian bleeding saps was $100 \%$ positive for all the samples collected in Emilia Romagna; while in Lazio, the direct PCR was positive in 30 and $40 \%$ in the first and last collected saps, respectively, and the nested PCR raised the detection of 80 and $100 \%$, respectively. In Veneto, the direct PCR was positive in 25,92 , and $25 \%$ of the saps collected from the first to the last sampling, and when the nested PCR was applied the percentages of detection were 75, 100, and 58\%, respectively (Table 2). Molecular results showing a similar behavior were obtained in samples from Chile, where the sap samples collected in Curicó, Chillán, and San Carlos were positive to the direct PCR in 14, 25, and $30 \%$, respectively, and when the nested PCR was applied, the positive samples were 71, 87, and 90\%, respectively (Table 2).

In Italy, the direct isolation of the bleeding sap samples collected in Emilia Romagna at the first and second sampling time detected P. syringae pv. actinidiae in 43 and $89 \%$ of them, respectively, on both NSA and SsNSA media. From the sap samples collected at the last collection time, $P$. syringae pv. actinidiae was isolated on NSA and on SsNSA in 9 and $46 \%$ of the samples, respectively. P. syringae pv. actinidiae was not isolated on the nutritive medium from the sap samples collected in Lazio at the first sampling time, while it was isolated from $8 \%$ of the samples on the semiselective medium. At the last collection time, the pathogen was isolated from 10 and $20 \%$ of the samples on NSA and SsNSA, respectively. P. syringae pv. actinidiae was isolated from sap samples collected in Veneto on both nutritive and semiselective media for $17 \%$ at the first sampling, and for $8 \%$ on both NSA and SsNSA at the other times of collection (Table 2). The sensitivity threshold of both NSA and SsNSA for the isolation of the pathogen was approximately $10^{2} \mathrm{CFU} / \mathrm{ml}$.

All isolated $P$. syringae pv. actinidiae strains belonged to the LOPAT group Ia and were levan positive, oxidase negative, potato 
rot negative, arginine dehydrolase negative, and HR positive, with the exception of two strains, IPV-BO 8893 and IPV-BO 9286, isolated in Emilia Romagna (from symptomatic kiwifruit plant) and Veneto (from asymptomatic kiwifruit plant), respectively, which were HR negative. The semiselective NSA medium was not employed for the direct isolations from Chilean samples and $P$. syringae pv. actinidiae was isolated on NSA from bleeding saps collected in Curicó, Chillán, and San Carlos in the 20,32, and 24\% of the samples, respectively.

MLSA and WGS. MLSA clustered Chilean and Italian isolates with $P$. syringae pv. actinidiae biovar 3 reference strains. Identical topology was obtained using ML and MP. In particular, HR negative samples showed a differentiation from biovar 3 reference strains only by a single nucleotide polymorphism in pgi gene (Fig. 1). Whole genome de novo assembly and genome annotation data for
P. syringae pv. actinidiae strains are shown in Table 3. Genome sizes of the sequenced strains ranged between 6.1 and $6.2 \mathrm{Mb}$ corresponding to a genome fold coverage that ranged from 207.6 to 270.8 , all of them having a $\mathrm{G}+\mathrm{C}$ content of $58.5 \%$. Local BLASTx analysis showed the absence of coronatine and $\arg K$ gene clusters that are associated with the synthesis of coronatine and phaseolotoxin, respectively. Phylogenetic analysis of concatenated T3SS genes showed no differences among Chilean and Italian isolates that clustered together in the group of biovar 3 strains. Sequence comparison of T3SS genes coding sequences did not show mutations or recombinations that could be associated with a loss of function of the coded proteins (Fig. 2). PAC_ICEs sequences obtained from HR negative isolates did not show differences with PAC_ICE2_It, kept as $P$. syringae pv. actinidiae Italian reference sequence (GenBank accession number KC148186). The same situation was observed in

TABLE 2. Results of molecular analyses and isolations from bleeding saps collected in Italy and Chile in springs

\begin{tabular}{|c|c|c|c|c|c|}
\hline \multirow[b]{2}{*}{ Region of bleeding sap collection } & \multirow{2}{*}{$\begin{array}{c}\text { Number } \\
\text { of sampling }\end{array}$} & \multicolumn{4}{|c|}{ Positive bleeding sap samples (\%) } \\
\hline & & PCR B1/B2 & PCR-nested KNF/KNR & Direct isolation on NSA & Direct isolation on SsNSA \\
\hline \multirow[t]{3}{*}{ Veneto, Italy } & I & 25 & 75 & 17 & 17 \\
\hline & II & 92 & 100 & 8 & 8 \\
\hline & III & 25 & 58 & 8 & 8 \\
\hline \multirow[t]{3}{*}{ Emilia-Romagna, Italy } & I & 100 & 100 & 43 & 89 \\
\hline & II & 100 & 100 & 43 & 89 \\
\hline & III & 100 & 100 & 9 & 46 \\
\hline \multirow[t]{2}{*}{ Lazio, Italy } & I & 30 & 80 & 0 & 8 \\
\hline & II & 40 & 100 & 10 & 20 \\
\hline Curicó - Maule, Chile & I & 14 & 71 & 20 & - \\
\hline Chillán - Biobío, Chile & I & 25 & 87 & 32 & - \\
\hline San Carlos - Biobío, Chile & I & 30 & 90 & 24 & - \\
\hline
\end{tabular}

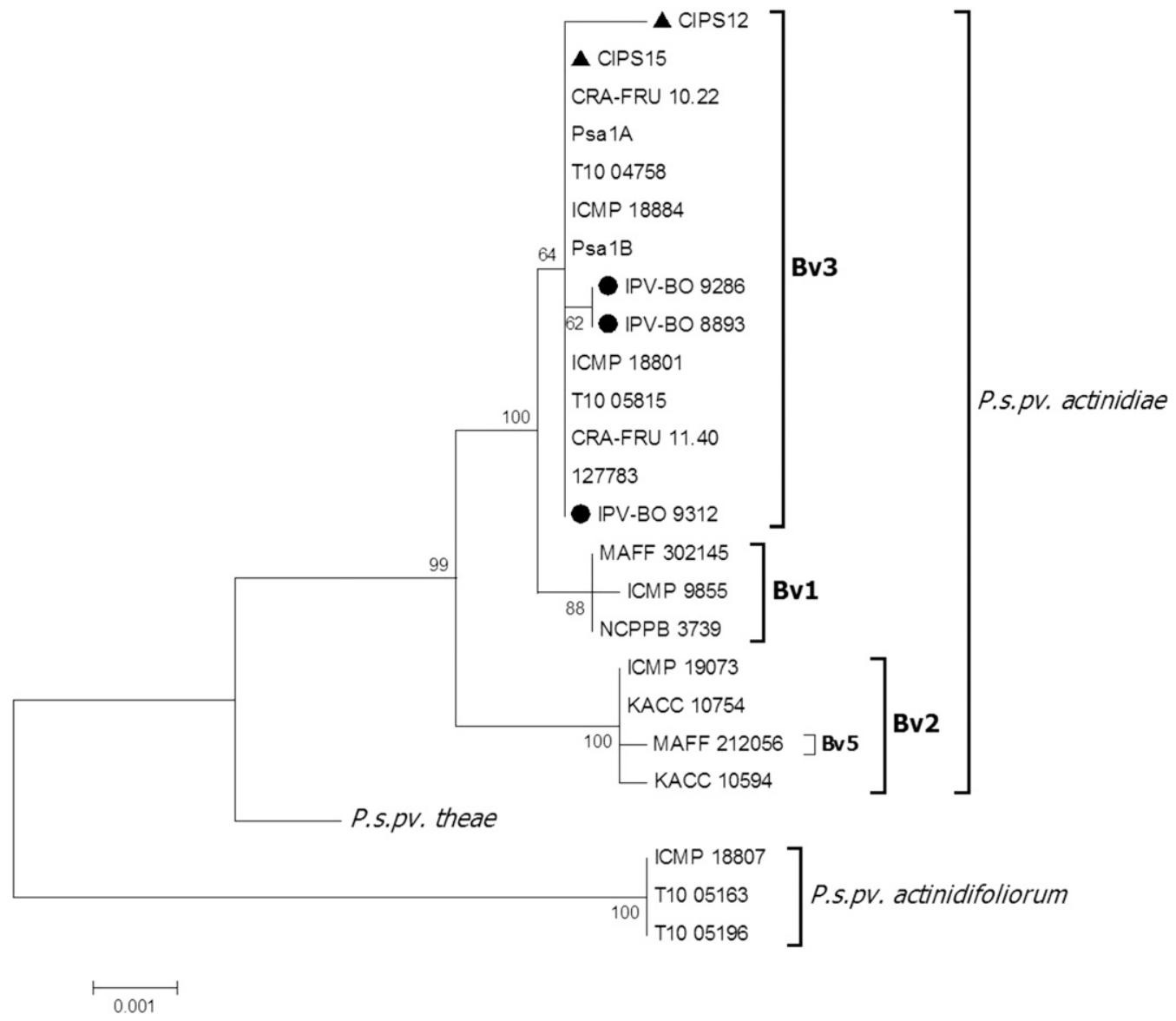

Fig. 1. Maximum likelihood phylogenetic tree of Pseudomonas syringae pv. actinidiae isolates, inferred from the concatenation of seven house-keeping genes (acn, cts, gapA, gyrB, pfk, pgi, and rpoB). Labels indicate the isolates obtained in this work ( Italian isolates; $\boldsymbol{\Delta}$ Chilean isolates). Numbers in nodes represent bootstrap values obtained from 500 replicates. 
Chilean isolates, showing identical nucleotide sequences to that of PAC_ICE3_cl, used as P. syringae pv. actinidiae Chilean reference sequence (GenBank accession number KC148188) (Fig. 3). Plasmid comparison showed $99.9 \%$ identity of the HR negative isolate IPV-BO 9286 with the plasmid of Chilean HR positive isolates and $99.8 \%$ identity of the HR negative isolate IPV-BO 8893 with the Italian HR positive isolates IPV-BO 9312 and CRA-FRU 14.08 used as reference (GenBank accession number CP019733). The $\arg K$ and coronatine gene clusters were not present in all Italian and Chilean strains of $P$. syringae pv. actinidiae biovar 3, both HR negative and positive strains (Fig. 4).

Pathogenicity assay and virulence evaluation of selected $P$. syringae pv. actinidiae strains. The disease severity of P. syringae pv. actinidiae strain IPV-BO 9312 (isolated in Veneto at the second sampling time) was the highest (approximately 14 spots/ leaf) compared with CFBP 7286 (reference strain, approximately 12 spots/leaf), IPV-BO 9266 (isolated in Emilia Romagna at the second sampling time, approximately 11 spots/leaf), CRA-FRU 3.1 (reference strain, approximately 10 spots/leaf), and IPV-BO 9294 (isolated in Lazio at the second sampling time, approximately 7 spots/leaf). The HR negative $P$. syringae pv. actinidiae strains IPVBO 9286 and IPV-BO 8893 resulted in low virulence, showing disease severities of approximately 0.3 and 0.5 spots/leaf, respectively, significantly similar to that caused by $P$. syringae $\mathrm{pv}$. actinidifoliorum strain ICMP 19074 (reference strain, approximately 0.9 spots/leaf). Control plants inoculated with SDW did not show any symptoms (Fig. 5).

\section{DISCUSSION}

The bleeding sap analyses on samples collected in the Italian and Chilean fields were confirmed to be a useful and fast method to early detection of $P$. syringae pv. actinidiae latent infections (Biondi et al. 2013). In addition, this study evaluated the time windows, in both hemispheres, suggesting optimal timing to collect sap samples directly from the kiwifruit plants to be before bud sprouts.

In Italy, the frequency of bleeding, in samples collected from the 12 selected plants in Veneto and Lazio, was high from the first collection time to the last one, ranging between approximately 83 and $100 \%$. Moreover, the average volume of bleeding saps collected in these two regions, from the third week of March (first collection time) to the second week of April (third collection time), was approximately 30 and $24 \mathrm{ml}$, respectively, and it was adequate for the subsequent microbiological and molecular analyses. In particular, in Veneto, the average bleeding volume showed a consistent decrease until the last collection time, where the mean volume was less than $20 \mathrm{ml}$, due to the beginning of bud sprouting. The average temperature during this time window reached approximately 9 and $11^{\circ} \mathrm{C}$ in Veneto and in Lazio, respectively (data not shown). On the contrary, the frequency of saps collected in Emilia Romagna was lower with respect to that calculated in Veneto and Lazio, and also the mean sap volume collected during the three collection times was significantly lower (approximately $10 \mathrm{ml}$ ). Since the mean temperature during all collection times in Emilia Romagna was approximately $9^{\circ} \mathrm{C}$, the reason for the lower frequency and the lower mean volume of sap samples collected might be due to the severity of the bacterial cankers in almost the entire kiwifruit field under observation. Several plants, in fact, showed abundant reddish exudates on the trunks branches before bud sprouting, and wilted shoots and leaves during the season, thus indicating the presence of high pathogen concentration in the xylem vessels (Balestra et al. 2009). The percentages of $P$. syringae pv. actinidiae isolations in fact was evaluated as approximately

TABLE 3. Genome de novo assembly and genome annotation data for the studied Pseudomonas syringae pv. actinidiae strains

\begin{tabular}{|c|c|c|c|c|c|c|c|c|}
\hline & GenBank accession number & Number of contigs & $\begin{array}{c}\text { Maximum } \\
\text { contig size (bp) }\end{array}$ & $\mathrm{N}_{50}(\mathrm{bp})$ & $\begin{array}{c}\text { Total } \\
\text { length (bp) }\end{array}$ & $\begin{array}{l}\text { Average } \\
\text { coverage }\end{array}$ & Predicted CDS & $\begin{array}{c}\text { Predicted } \\
\text { RNAs }\end{array}$ \\
\hline IPV-BOy 8893 & PEIN00000000 & 297 & 141.708 & 42.770 & 6.175 .775 & $160 \times$ & 5.529 & 61 \\
\hline IPV-BO 9286 & PEIO00000000 & 296 & 141.707 & 43.968 & 6.171 .732 & $165 x$ & 5.533 & 60 \\
\hline IPV-BO 9312 & PEIP00000000 & 310 & 141.790 & 43.897 & 6.133 .400 & $180 \times$ & 5.490 & 62 \\
\hline $\mathrm{PS}^{\mathrm{z}} 12$ & PEHG00000000 & 317 & 141.707 & 43.856 & 6.142 .385 & $170 \times$ & 5.524 & 66 \\
\hline PS 15 & PEHP00000000 & 300 & 141.707 & 43.602 & 6.120 .148 & $168 \times$ & 5.486 & 62 \\
\hline
\end{tabular}

y IPV-BO: strains of the bacterial collection of Department of Agricultural Sciences, University of Bologna.

z PS: strains of the bacterial collection of Departamento de Sanidad Vegetal, Facultad de Ciencias Agronómicas, Universidad de Chile.

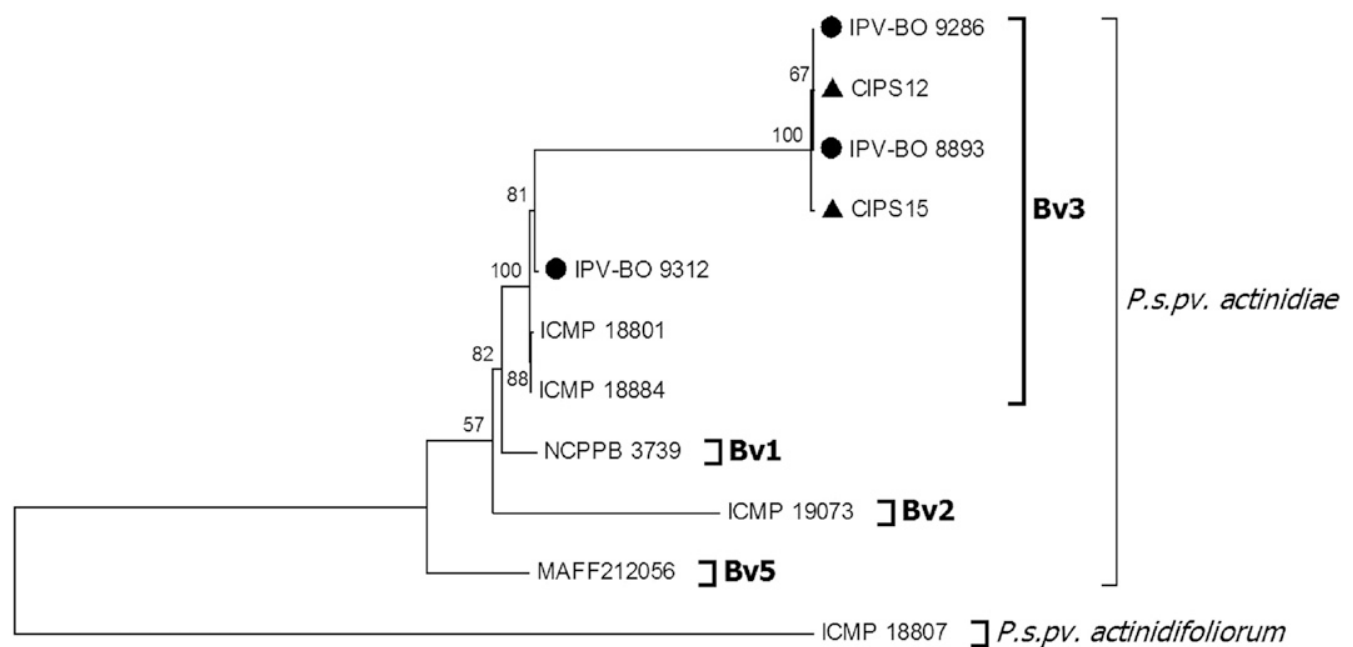

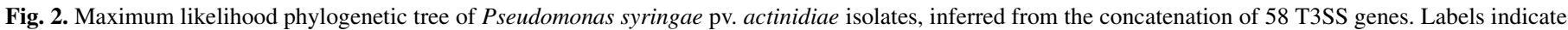
the isolates obtained in this work (Italian isolates; $\Delta$ Chilean isolates). Numbers in nodes represent bootstrap values obtained from 250 replicates. 
$89 \%$ in the first two series (times I and II) of collection samples. Moreover, during the previous year (2012), bleeding sap samples from the same field were collected with a frequency of 14/14 with a mean sap volume of approximately $10 \mathrm{ml}$, and $P$. syringae $\mathrm{pv}$. actinidiae was detected with PCR and nested-PCR at 21 and $28 \%$, respectively (Biondi et al. 2013), thus demonstrating the increase of $P$. syringae pv. actinidiae population in the xylem vessels.

In Chile, all sap samples were collected during the first 10 days of October (spring in the southern hemisphere), and therefore in parallel with the last period (approximately 15 to 20 days) of

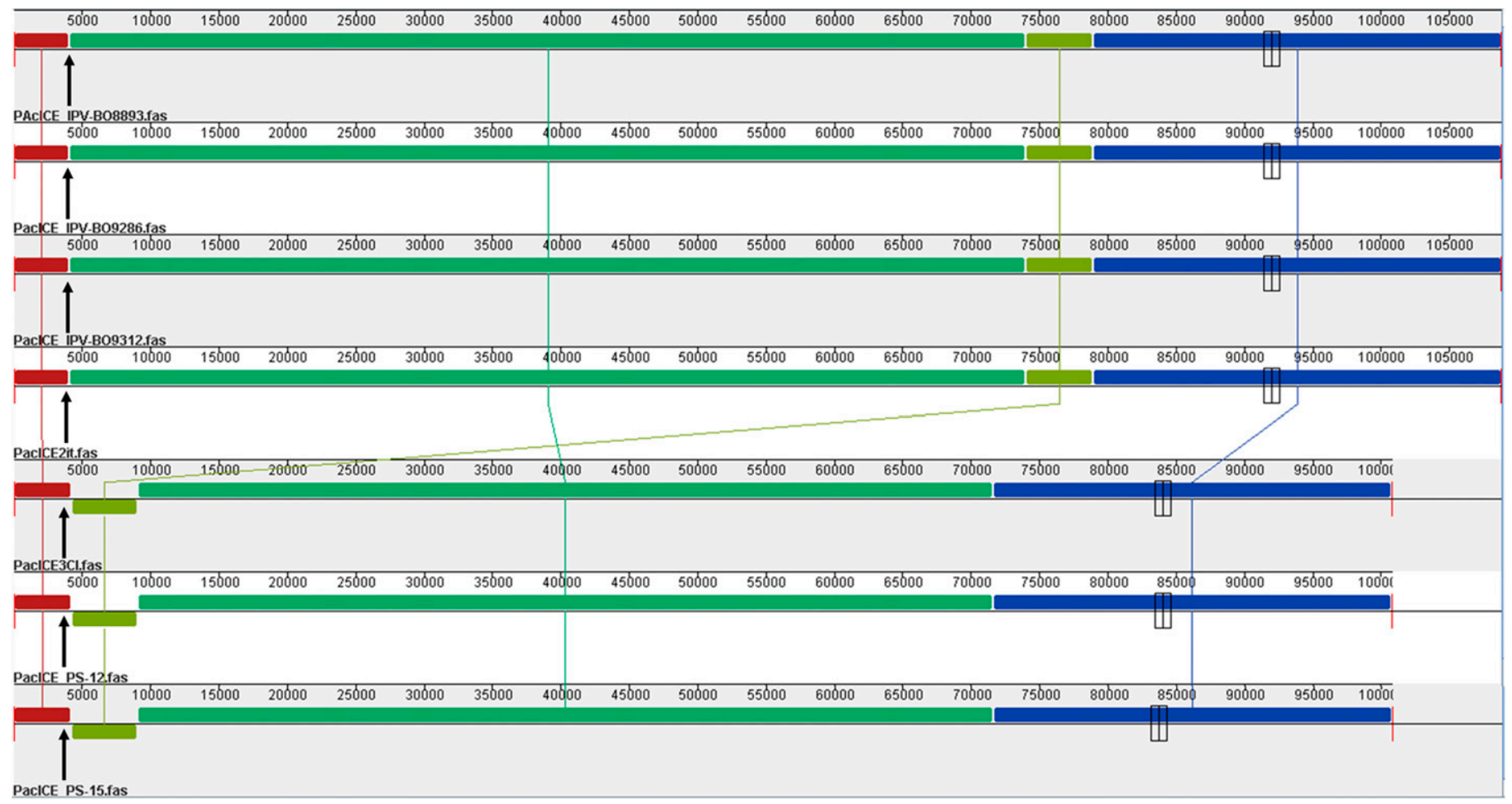

Fig. 3. MAUVE alignment diagram of PAC_ICE sequences of Italian (IPV-BO 8893, IPV-BO 9286, and IPV-BO 9312) and Chilean (PS 12 and PS 15) Pseudomonas syringae pv. actinidiae strains aligned to Italian and Chilean reference sequences PacICE2it (KC148186) and PacICE3Cl (KC148188).

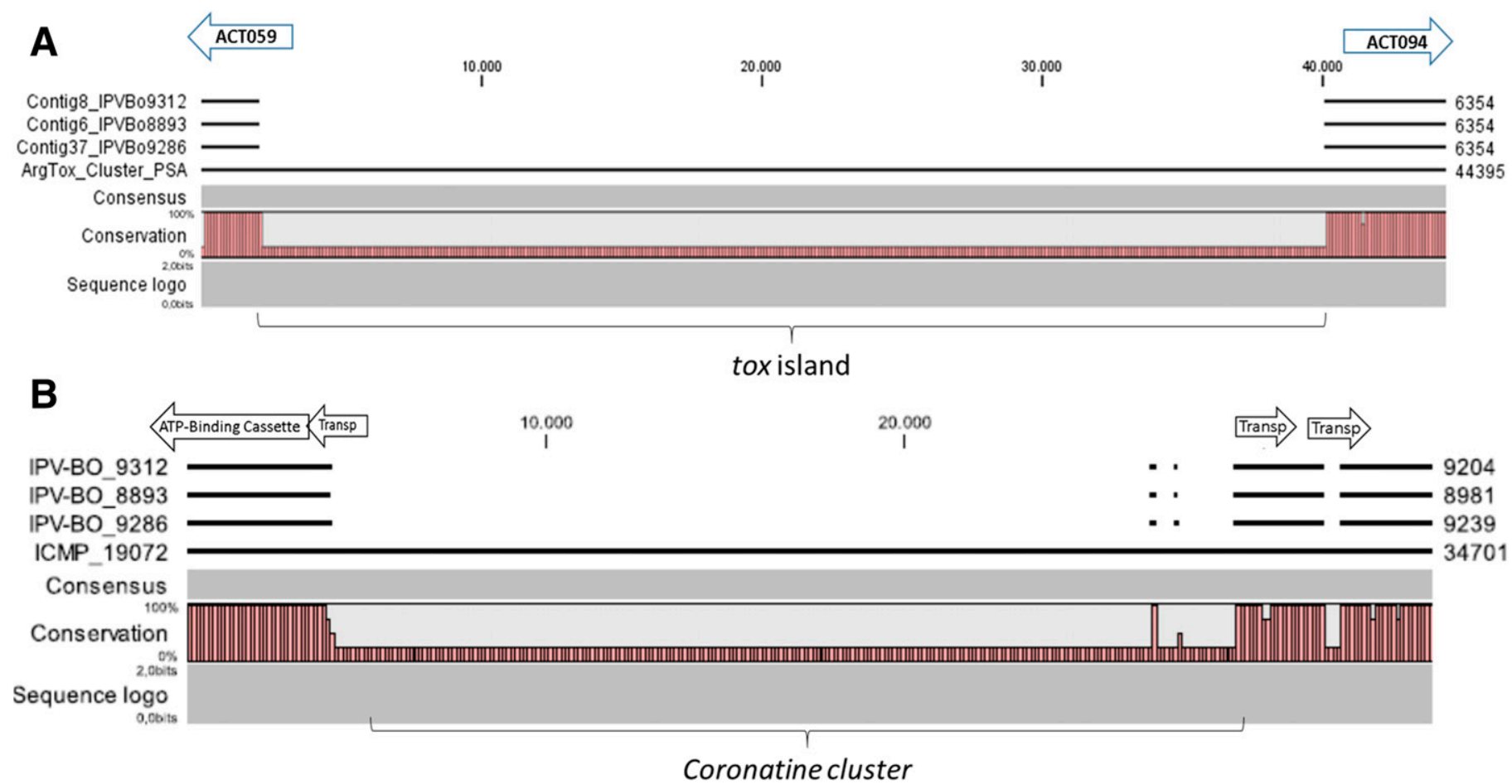

Fig. 4. Comparative analysis of biovar 3 strains from Italy enclosing both HR positive (IPV-BO 9312) and HR negative (IPV-BO 8893, IPV-BO 9286) isolates. Results, obtained by CLC genomics workbench alignment tool, are as follows: A, the lack of the genomic island containing $\arg K$ cluster (phaseolotoxin synthesis gene cluster) of three Italian strains compared with reference strain NCPPB 3739 (biovar 1) and in B, the lack of island containing the coronatine cluster of the three strains compared with reference strain ICMP 19072 (biovar2). 
collection times carried out in Italy during the vegetative season of the north hemisphere. The mean temperatures during such period were evaluated at approximately $14^{\circ} \mathrm{C}$. The frequency of collected bleeding saps was high, ranging from 70 to $100 \%$, and the sap volumes reached a mean of approximately $20 \mathrm{ml}$, not as high as those collected in Italy, in particular in Veneto and Lazio, but statistically similar among the three fields employed for the trials.

The molecular analyses carried out in Italy showed an overestimation of the $P$. syringae pv. actinidiae detection percentage when compared with results of microbiological analyses through the pathogen isolation on nutritive and semiselective media. This difference was observed in all sap samples collected in the three regions during the whole collection time window. The bleeding saps collected in Emilia Romagna infected fields during the three collection times were found to be $100 \%$ positive for $P$. syringae pv. actinidiae by PCR and nested-PCR. The microbiological analyses allowed the detection of the pathogen in 89 and $46 \%$ of the samples collected during the first two and the third collection times, respectively, by using the semiselective medium. Also, the samples collected from asymptomatic plants in Veneto and Lazio fields were found to be 60 to $100 \%$ positive for $P$. syringae pv. actinidiae by molecular analyses, while isolation of the pathogen was only possible in 8 to $20 \%$ of the saps. As expected, considering the additional antibiotics, SsNSA was always more effective in pathogen isolation compared with NSA medium, through the reduction of bacterial and fungal contamination.

Approximately 4 weeks before bud sprouting, from the end of March to the beginning of April 2013, the pathogen concentration increased, allowing its isolation from the saps originated by the most severely infected/symptomatic plants. However, the population of bacterial endophytes increased as well and it interfered with the pathogen isolation when the nutritive medium was used. The absence of antibiotic in NSA allowed the growth of faster bacterial contaminants inhibiting the $P$. syringae pv. actinidiae growth
(EPPO 2014). In Chile as well, similar results were obtained from all bleeding sap samples; thus, molecular analyses were 70 to $90 \%$ $P$. syringae pv. actinidiae-positive, while the pathogen was isolated on nutritive medium only in 20 to $30 \%$ of the cases.

Similar studies were carried out in the 1980s (Burr and Katz 1983) and later in the 2000s (Flamini et al. 2006; Szegedi and Bottka 2002) on Agrobacterium vitis, the causal agent of the monocyclic disease grapevine crown gall, aimed to the detection of tumorigenic $A$. vitis strains from sap samples collected from asymptomatic plants during the grapevine bleeding at the beginning of the vegetative growth. Such studies revealed the efficacy of the method in the detection of $A$. vitis latent infections. In the case of $P$. syringae pv. actinidiae, which is a polycyclic pathogen, the early detection through bleeding sap analysis and immediate removal of infected plants might raise the possibility to reduce the numerous inoculum sources.

The discrepancy between molecular and microbiological analyses could be explained by the low sensitivity of the media used for the isolation. Both media in fact, NSA and SsNSA, showed a sensitivity threshold of approximately 30 to $100 \mathrm{CFU} / \mathrm{ml}$. In several cases, the pathogen present at low population level was detected by the molecular assay, but it cannot be isolated. Moreover, the sensitivity threshold on NSA was reduced by the presence of several bacterial contaminant species that affected the colony recognition, or in the worst cases, the growth of the culture. The antibiotics contained in SsNSA enhanced the effectiveness of $P$. syringae pv. actinidiae isolation; however, the sensitivity threshold was not improved. The lack of sensitivity of an isolation medium considerably limits the diagnostic analysis and it might also affect alternative molecular methods, which are usually combined with isolation methods to increase the sensitivity threshold for the pathogen detection: e.g., bio-PCR for Acidovorax citrulli and A. vitis detection (Bini et al. 2008; Feng et al. 2013). The medium KBC (Mohan and Schaad 1987) is considered more effective in the $P$. syringae

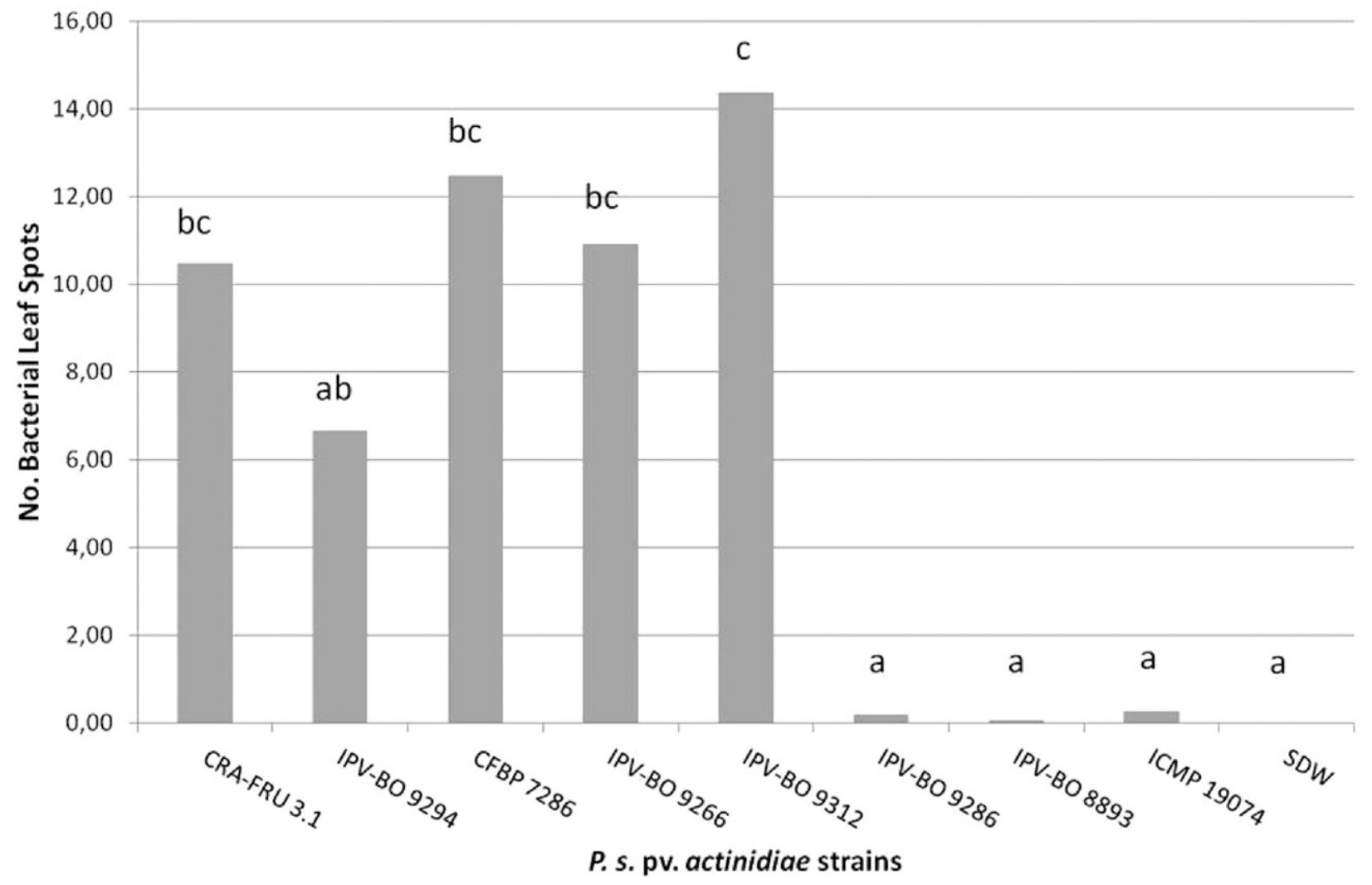

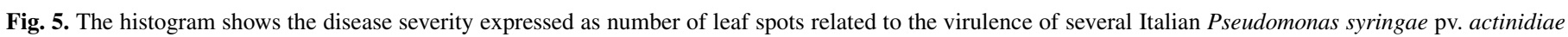

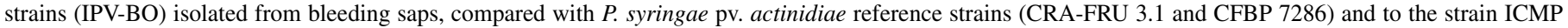
19074 of $P$. syringae pv. actinidifoliorum. SDW: Sterile distilled water. Different letters indicate different statistical categories (Duncan's test, $P \leq 0.05$ ). 
pv. actinidiae isolation. However, it does not show colonies with differential characteristics in the colony morphology; P. syringae pv. actinidiae, in fact, does not produce fluorescent pigments (Balestra et al. 2009; Scortichini 1994). Therefore, NSA was selected for this study. P. syringae pv. actinidiae colonies grown on NSA were levan positive, allowing for easier recognition among the saprophytes.

Despite the biologic differences obtained in the pathogenicity assays, the MLSA and WGS analyses did not show significant differences between the WGS of the HR negative and HR positive strains. The Italian strain IPV-BO 9312, which resulted in the most virulent strain, did not show significant differences in the T3SS genes among all Chilean and Italian strains of $P$. syringae pv. actinidiae biovar 3; in particular, the strain IPV-BO 9312 showed the T3SS gene cluster significantly similar to that of HR negative IPV-BO 8893 and IPV-BO 9286, hypovirulent $P$. syringae pv. actinidiae strains. According to previous studies, PAC_ICE sequences included open reading frames associated with adaptability of the strains with the environment and also possible characteristics related to pathogenicity. The almost-identical sequences obtained for HR positive and negative Italian strains, and also identical to Italian reference PAC_ICE sequence, clearly showed that the genetic explanation of the distinct pathogenic phenotype is located in other genomic regions. As expected, Italian and Chilean strains showed different PAC_ICE sequences; however, they were identical to each country reference: PAC_ICE2 from Italy and PAC_ICE3 from Chile (Butler et al. 2013). In addition, as for the $P$. syringae pv. actinidiae strains belonging to biovar 3 (Sawada et al. 1995), no $\arg K$ and coronatine gene clusters were detected in hypovirulent strains IPV-BO 8893 and IPV-BO 9286. As T3SS associated genes showed no differences in nucleotide sequences, the low pathogenicity observed in HR negative strains IPV-BO 8893 and IPV-BO 9286 could not be associated with mutations that could alter the protein structure as previously reported in $P$. syringae isolates (Mohr et al. 2008). Results reported by Diallo et al. (2012) indicated that differences in hypersensitivity tests lay in the absence of at least one of the genes contained in the hrp/hrc locus. On the contrary, in this study the structure of the $h r p / h r c$ locus was the same in all the Italian strains, even though their virulence varied. Also, the gene hopA1, which differentiated the $P$. syringae pv. actinidiae strains biovar 1 from those belonging to biovar 3 (Vanneste et al. 2011), were present without polymorphisms in HR negative $P$. syringae pv. actinidiae strains as well. According to Diallo et al. (2012), HR negative strains of $P$. syringae pv. syringae have been frequently found in different nonagricultural matrices and their association with lack of pathogenicity was not as strict as it appeared, showing that some HR negative strains caused similar severe symptoms in cantaloupe to those observed by HR positive strains. These observations lead to the hypothesis that the hypovirulence observed could be not associated with T3SS genes, but to genes associated with environmental response and adaptation, or in response to the host gene transcripts, whose increase was reported a few hours after pathogen inoculation (Michelotti et al. 2015). Thus, regulatory regions of different pathogenicity genes have to be more deeply explored in order to associate a possible alteration in gene expression to the lack of HR.

\section{ACKNOWLEDGMENTS}

We thank the owners of the Italian and Chilean fields whose availability allowed us to monitor their plants for 3 years and permitted the production of this study.

\section{LITERATURE CITED}

Anonymous. 2011a. Bacterial canker, kiwifruit-Chile: First report (O’Higgins, Maule). ProMED mail. International Society for Infectious Disease. Archive no. 20110325.0940
Anonymous. 2011b. First record of Pseudomonas syringae pv. actinidiae in Australia. EPPO Rep. Serv. 6:130.

Abelleira, A., López, M. M., Peñalver, J., Casal, O. A., Mansilla, J. P., Montoussé, A. P., and Garcia, M. J. 2011. First report of bacterial canker of kiwifruit caused by Pseudomonas syringae pv. actinidiae in Spain. Plant Dis. 95:1583.

Balestra, G. M., Mazzaglia, A., Quattrucci, A., Renzi, M., and Rossetti, A. 2009. Current status of bacterial canker spread on kiwifruit in Italy. Australas. Plant Dis. Notes 4:34-36.

Balestra, G. M., Mazzaglia, A., Spinelli, R., Graziani, S., Quattrucci, A., and Rossetti, A. 2008. Cancro batterico su Actinidia chinensis. Inf. Agrar. 38: 75-76.

Balestra, G. M., Renzi, M., and Mazzaglia, A. 2011. First report of Pseudomonas syringae pv. actinidiae on kiwifruit plants in Spain. New Dis. Rep. 24:10.

Balestra, G. M., Taratufolo, M. C., Vinatzer, B. A., and Mazzaglia, A. 2013. A multiplex PCR assay for detection of Pseudomonas syringae pv. actinidiae and differentiation of populations with different geographic origin. Plant Dis. 97:472-478.

Bini, F., Kuczmog, A., Putnoky, P., Otten, L., Bazzi, C., Burr, T. J., and Szegedi, E. 2008. Novel pathogen-specific primers for the detection of Agrobacterium vitis and Agrobacterium tumefaciens. Vitis 47:181-189.

Biondi, E., Galeone, A., Kuzmanovic, N., Ardizzi, S., Lucchese, C., and Bertaccini, A. 2013. Pseudomonas syringae pv. actinidiae detection in kiwifruit plant tissue and bleeding sap. Ann. Appl. Biol. 162:60-70.

Biondi, E., Perez, S., Giuliani, D., Comuzzo, G., Testolin, R., and Bertaccini, A. 2015. II Psa Symposium, Bologna, Book of Abstracts 67. DipSA, University of Bologna, Italy.

Buriani, G., Hadersdorfer, J., Treutter, D., and Spinelli, F. 2015. Use of loop-mediated isothermal amplification (LAMP) as diagnosis tool to identify Psa in open field. II Psa Symposium, Bologna, Book of Abstracts 70. DipSA, University of Bologna, Italy.

Burr, T. J., and Katz, B. H. 1983. Isolation of Agrobacterium tumefaciens biovar 3 from grapevine galls and sap, and from vineyard soil. Phytopathology 73:163-165.

Butler, M. I., Stockwell, P. A., Black, M. A., Day, R. C., and Lamont, I. L. 2013. Pseudomonas syringae pv. actinidiae from recent outbreaks of kiwifruit bacterial canker belong to different clones that originated in China. PLoS One 8:e57464.

Cellini, A., Fiorentini, L., Buriani, G., Yu, J., Donati, I., Cornish, D. A., Novak, B., Costa, G., Vanneste, J. L., and Spinelli, F. 2014. Elicitors of the salicylic acid pathway reduce incidence of bacterial canker of kiwifruit caused by Pseudomonas syringae pv. actinidiae. Ann. Appl. Biol. 165:441-453.

Chapman, J. R., Taylor, R. K., Weir, B. S., Romberg, M. K., Vanneste, J. L., Luck, J., and Alexander, B. J. R. 2012. Phylogenetic relationships among global populations of Pseudomonas syringae pv. actinidiae. Phytopathology 102:1034-1044

Ciarroni, S., Gallipoli, L., Taratufolo, M. C., Butler, M. I., Poulter, R. T. M., Pourcel, C., Vergnaud, G., Balestra, G. M., and Mazzaglia, A. 2015. Development of a multiple loci variable number of tandem repeats analysis (MLVA) to unravel the intra-pathovar structure of Pseudomonas syringae pv. actinidiae populations worldwide. PLoS One 10:e0135310.

Crosse, J. E. 1959. Bacterial canker of stone-fruits: IV. Investigation of a method for measuring the inoculum potential of cherry trees. Ann. Appl. Biol. 47:306-317.

Cunty, A., Cesbron, S., Poliakoff, F., Jacques, M. A., and Manceau, C. 2015b. The origin of the outbreak in France of Pseudomonas syringae pv. actinidiae biovar 3, the causal agent of bacterial canker of kiwifruit, revealed by a multilocus variable-number of tandem repeat analysis. Appl. Environ. Microbiol. 81:6773-6789.

Cunty, A., Poliakoff, F., Rivoal, C., Cesbron, S., Fischer-Le Saux, M., Lemaire, C., Jacques, M. A., Manceau, C., and Vanneste, J. L. 2015a. Characterization of Pseudomonas syringae pv. actinidiae (Psa) isolated from France and assignment of strains Psa biovar 4 to a de novo pathovar: Pseudomonas syringae pv. actinidifoliorum. Plant Pathol. 64:582-596.

de Boer, S. H., Ward, L. J., Li, X., and Chittaranjan, S. 1995. Attenuation of PCR inhibition in the presence of plant compounds by addition of BLOTTO. Nucleic Acids Res. 23:2567-2568.

Diallo, M. D., Monteil, C. L., Vinatzer, B. A., Clarke, C. R., Glaux, C., Guilbaud, C., Desbiez, C., and Morris, C. E. 2012. Pseudomonas syringae naturally lacking the canonical type III secretion system are ubiquitous in nonagricultural habitats, are phylogenetically diverse and can be pathogenic. ISME J. 6:1325-1335.

EPPO. 2014. PM 7/120 (1) Pseudomonas syringae pv. actinidiae. OEPP/EPPO Bull. 44(3):360-375.

Everett, K. R., Taylor, R. K., Romberg, M. K., Rees-George, J., Fullerton, R. A., Vanneste, J. L., and Manning, M. A. 2011. First report of Pseudomonas syringae pv. actinidiae causing kiwifruit bacterial canker in New Zealand. Australas. Plant Dis. Notes 6:67-71. 
Feng, J. J., Li, J. Q., Walcott, R. R., Zhang, G. M., Luo, L. X., Kang, L., Zheng, Y., and Schaad, N. W. 2013. Advances in detection of Acidovorax citrulli, the causal agent of bacterial fruit blotch of cucurbits. Seed Sci. Technol. 41:1-15.

Flamini, L., Rossini, E., Tonti, S., Biondi, E., Sandalo, S., Bini, F., Nipoti, P., and Bazzi, C. 2006. Detection of endophytic microorganisms within rootstock mother vines grown in the Marche. J. Plant Pathol.: S31-S63.

Fujikawa, T., and Sawada, H. 2016. Genome analysis of the kiwifruit canker pathogen Pseudomonas syringae pv. actinidiae biovar 5. Sci. Rep. 6:21399.

Gallelli, A., L'Aurora, A., and Loreti, S. 2011. Gene sequence analysis for the molecular detection of Pseudomonas syringae pv. actinidiae: Developing diagnostic protocols. J. Plant Pathol. 93:425-435.

Gallelli, A., Talocci, S., Pilotti, M., and Loreti, S. 2014. Real-time and quantitative PCR for detecting Pseudomonas syringae pv. actinidiae isolates causing recent outbreaks of kiwifruit bacterial canker. Plant Pathol. 63: 264-276.

King, E. O., Raney, M. K., and Ward, D. E. 1954. Two simple media for the demonstration of pyocianin and fluorescin. J. Lab. Clin. Med. 44:301-307.

Koh, H. S., Kim, G. H., Lee, Y. S., Koh, Y. J., and Jung, J. S. 2014. Molecular characteristics of Pseudomonas syringae pv. actinidiae strains isolated in Korea and a multiplex PCR assay for haplotype differentiation. Plant Pathol. J. 30:96-101.

Koh, J. K., and Nou, I. S. 2002. DNA markers for the identification of Pseudomonas syringae pv. actinidiae. Mol. Cells 13:309-314.

Koh, Y. J., Cha, B. J., Chung, H. J., and Lee, D. H. 1994. Outbreak and spread of bacterial canker in kiwifruit. Korean J. Plant Pathol. 10:68-72.

Kumar, S., Stecher, G., and Tamura, K. 2016. MEGA7: Molecular evolutionary genetics analysis version 7.0 for bigger datasets. Mol. Biol. Evol. $33: 1870-1874$

Lelliot, R. A., and Stead, D. E. 1987. Methods for the Diagnosis of Bacterial Disease of Plants. British Society for Plant Pathology. Blackwell Scientific Publications, Oxford, UK.

Marcelletti, S., Ferrante, P., Petriccione, M., Firrao, G., and Scortichini, M. 2011. Pseudomonas syringae pv. actinidiae draft genomes comparison reveal strain-specific features involved in adaptation and virulence to Actinidia species. PLoS One 6:e27297.

Mazzaglia, A., Studholme, D. J., Taratufolo, M. C., Cai, R., Almeida, N. F., Goodman, T., Guttman, D. S., Vinatzer, B. A., and Balestra, G. M. 2012. Pseudomonas syringae pv. actinidiae (Psa) isolates from recent bacterial canker of kiwifruit outbreaks belong to the same genetic lineage. PLoS One 7:e36518.

McCann, H. C., Rikkerink, E. H. A., Bertels, F., Fiers, M., Lu, A., Rees-George, J., Andersen, M. T., Gleave, A. P., Haubold, B., Wohlers, M. W., Guttman, D. S., Wang, P. W., Straub, C., Vanneste, J. L., Rainey, P. B., and Templeton, M. D. 2013. Genomic analysis of the kiwifruit pathogen Pseudomonas syringae pv. actinidiae provides insight into the origins of an emergent plant disease. PLoS One 9:e1003503.

Michelotti, V., Lamontanara, A., Orrù, L., Buriani, G., Cellini, A., Donati, I., Vanneste, J., Cattivelli, L., Spinelli, F., and Tacconi, G. 2015. Deciphering kiwifruit transcriptome during the infection by Pseudomonas syringae pv. actinidiae (Psa). II Psa Symposium, Bologna, Book of abstracts 21. DipSA, University of Bologna, Italy.

Mohan, S. K., and Schaad, N. W. 1987. An improved agar plating assay for detecting Pseudomonas syringae pv. syringae and $P$. s. pv. phaseolicola in contaminated bean seed. Phytopathology 77:1390-1395.

Mohr, T. J., Liu, H., Yan, S., Morris, C. E., Castillo, J. A., Jelenska, J., and Vinatzer, B. 2008. Naturally occurring non-pathogenic isolates of the plant pathogen species Pseudomonas syringae lack a type III secretion system and effector gene orthologues. J. Bacteriol. 190:2858-2870.

NPPO of Switzerland. 2011-08. http://archives.eppo.int/EPPOReporting/2011/ Rse-1108.pdf

Rees-George, J., Vanneste, J., Cornish, D. A., Pushparajah, I. P. S., Yu, J., Templeton, M. D., and Everett, K. R. 2010. Detection of Pseudomonas syringae pv. actinidiae using polymerase chain reaction (PCR) primers based on the 16S-23S r DNA intertrascribed spacer region and comparison with PCR primers based on other gene regions. Plant Pathol. 59:453-464.

Ruinelli, M., Schneeberger, P. H. H., Ferrante, P., Bühlmann, A., Scortichini, M., Vanneste, J. L., Duffy, B., and Pothier, J. F. 2017. Comparative genomicsinformed design of two LAMP assays for detection of the kiwifruit pathogen Pseudomonas syringae pv. actinidiae and discrimination of isolates belonging to the pandemic biovar 3. Plant Pathol. 66:140-149.

SAG. 2011. First report of bacterial canker of kiwifruit in Chile. Government of Chile. www.cooperativa.cl/sag-prepara-plan-de-contingenciatras-deteccion-de-enfermedad-del-kiwi-en-chile/prontus nots/2011-03-22/ 093651.html

Sarkar, S., and Guttman, D. 2004. Evolution of the core genome of Pseudomonas syringae, a highly clonal, endemic plant pathogen. Appl. Environ. Microbiol. 70:1999-2012.

Sawada, H., Miyoshi, T., and Ide, Y. 2014. Novel MLSA group (Psa5) of Pseudomonas syringae pv. actinidiae causing bacterial canker of kiwifruit (Actinidia chinensis) in Japan. Jpn. J. Phytopathol. 80:171-184.

Sawada, H., Suzuki, F., Matsuda, I., and Saitou, N. 1995. Phylogenetic analysis of Pseudomonas syringae pathovars suggests the horizontal gene transfers of $\arg K$ and the evolutionary stability of hrp gene cluster. J. Mol. Evol. 49:627-644.

Schaad, N. W., Jones, J. B., and Chun, W. (eds.) 2001. Laboratory Guide for Identification of Plant Pathogenic Bacteria, 3rd ed. American Phytopathological Society, St. Paul, MN.

Scortichini, M. 1994. Occurrence of Pseudomonas syringae pv. actinidiae on kiwifruit in Italy. Plant Pathol. 43:1035-1038.

Serizawa, S., Ichikawa, T., Takikawa, Y., Tsuyumu, S., and Goto, M. 1989. Occurrence of bacterial canker of kiwifruit in Japan: Description of symptoms, isolation of the pathogen and screening of bactericides. Ann. Phytopathol. Soc. Jpn. 55:427-436.

Stefani, E., and Giovanardi, D. 2011. Dissemination of Pseudomonas syringae pv. actinidiae through pollen and its epiphytic life on leaves and fruits. Phytopathol. Mediterr. 50:489-496.

Szegedi, E., and Bottka, S. 2002. Detection of Agrobacterium vitis by polymerase chain reaction in grapevine bleeding sap after isolation on a semiselective medium. Vitis 41:37-42.

Takikawa, Y., Serizawa, S., Ichikawa, T., Tsuyumu, S., and Goto, M. 1989. Pseudomonas syringae pv. actinidiae pv. nov.: The causal bacterium of canker of kiwifruit in Japan. Ann. Phytopathol. Soc. Jpn. 55:437-444.

Vanneste, J. L., Cornish, D. A., Yu, J., Audusseau, C., Paillard, S., Rivoal, C., and Poliakoff, F. 2011. Presence of the effector gene hopAl in strains of Pseudomonas syringae pv. actinidiae isolated from France and Italy. N. Z. J. Plant Prot. 64:252-258.

Vanneste, J. L., Yu, J., and Cornish, D. A. 2010. Molecular characterization of Pseudomonas syringae pv. actinidiae strains isolated from the recent outbreak of bacterial canker of kiwifruit in Italy. N. Z. J. Plant Prot. 63:7-14.

Vanneste, J. L., Yu, J., Cornish, D. A., Tanner, D. J., Windner, R., Chapman, J. R., Taylor, R. K., Mackay, J. F., and Dowlut, S. 2013. Identification, virulence, and distribution of two biovars of Pseudomonas syringae pv. actinidiae in New Zealand. Plant Dis. 97:708-719. 